\title{
Influence of Multiple Interactions in Value Cocreation on Sports Spectators' Perceived Value of Sports Events
}

\author{
Zhigang Wang $\mathbb{D}^{1},{ }^{1}$ Rui Cao, ${ }^{2}$ Xintao Liu, ${ }^{3}$ Lei Zhang, ${ }^{3}$ and Chao Wang \\ ${ }^{1}$ Economy and Management Department of Wuhan Sports University, Wuhan 430079, Hubei, China \\ ${ }^{2}$ Management School of Shanghai University, Shanghai 201800, China \\ ${ }^{3}$ Wuhan Sports University, Wuhan 430079, Hubei, China \\ Correspondence should be addressed to Zhigang Wang; wzg771102@163.com
}

Received 18 March 2021; Revised 3 July 2021; Accepted 23 November 2021; Published 20 December 2021

Academic Editor: Giacomo Fiumara

Copyright ( $) 2021$ Zhigang Wang et al. This is an open access article distributed under the Creative Commons Attribution License, which permits unrestricted use, distribution, and reproduction in any medium, provided the original work is properly cited.

This study analyzed the effects of multiple interactions in value cocreation activities involving sports spectators. Interaction activities for value cocreation at sports events comprise spectator-athlete and spectator-staff interactions. A survey of spectators at the 2017 Wuhan Open revealed that spectator-athlete and spectator-staff interactions increased spectator perceived value, which in turn increased spectator satisfaction and loyalty. Spectator-staff interactions had a greater effect on spectator sports event value than did spectator-athlete interactions. Therefore, organizers of sports events should effectively manage multiple value cocreation interactions to improve spectator satisfaction and loyalty. The present study's consideration of the effect of multiple interactions in value cocreation extends value cocreation theory.

\section{Introduction}

Value cocreation theory is based on service-dominant logic (SDL) and states that value is not created independently by a company [1]. From the conventional production-oriented perspective, value is created through the production process within a firm. However, from the perspective of SDL, the consumer is a coproducer of goods and is thus a cocreator of value [1]. The interaction between providers and buyers can create customer value; this has become a central tenet of marketing [2].

Studies have investigated value cocreation in sports events. In such contexts, spectators are both customers and participants in value cocreation [3]. They contribute revenue for sports events and are considered as service coproducers and value cocreators [4]. During sports events, spectators may chant, sing songs, perform choreographed dance routines, or hang banners within and around a stadium. These activities substantially add to the value created [5].

Context plays a pivotal role in the value cocreation process and determines the actors participating in value cocreation [6]. Value in sports events [7] is created by multiple firm or organization actors (e.g., sports teams, leagues, event organizers, or the media); in such events, value for spectators is created through the interaction between spectators and such actors. Value cocreation between spectators and actors in the context of sports events substantially differs from value cocreation in the context of a conventional firm. Conventionally, value cocreation occurs because of interactions between customers and a firm [1]. However, for sports events, value for spectators is created through interactions of spectators with organizers, athletes, teams, or the media; the number of participants in this cocreation process is greater than that in the context of a conventional firm [5]. These multiple interactions result in spectator value cocreation in sports events.

The objective of the present study was to investigate the mechanisms through which the interactions of spectators with organizers, athletes, teams, or the media during value cocreation influence spectator satisfaction and loyalty in the context of watching a live sports event. Specifically, we explored the effects of spectator-staff and spectator-athlete interactions on spectator perceived value, satisfaction, and loyalty. 
This study makes three theoretical contributions. First, the mechanisms underlying value cocreation among sports spectators were described, thus contributing to research on value cocreation in sports events. Second, the role of spectator perceived value in value cocreation in the context of sports events was determined, further extending the literature by elucidating the mechanisms underlying the influence of value cocreation in sports events on the responses of spectators. Third, the effects of multiple interactions on value cocreation among sports event spectators were explored, thus deepening the theory of value cocreation.

\section{Literature Review}

2.1. Value Cocreation. As mentioned, value cocreation theory is based on SDL. According to SDL, service is the most universal feature of exchange processes [1]. Moreover, from the perspective of SDL, the process of value creation involves the consumers of a product or service rather than producers alone [8]; specifically, consumers are value cocreators [9]. Products and services are valuable only when they are used; hence, consumer experiences and perceptions are key determinants of value, and consumers are cocreators of value [1].

Value cocreation involves value cocreation activities that occur between enterprises and consumers and the effects of these activities. In product design, consumer emotional involvement, self-service, consumer experience, consumer choice, and consumer participation constitute the essence of value cocreation [10]. During the process of value cocreation, consumers are transformed from conventional "passive recipients" of value to "active participants" in value cocreation $[11,12]$. Value cocreation theory posits that value exists in the personalized experience of the consumer, and value is thus created through that experience [8]. Value cocreation activities not only require consumers to participate in traditional corporate activities but also require enterprises to participate in the process of consumer product use $[13,14]$. Consumers can be invited to participate as coproducers in production processes that are conventionally controlled by enterprises $[15,16]$. Conversely, enterprises can also be invited to participate as value cocreators in consumer-controlled, experience-based value creation processes.

The interactions between enterprises and consumers constitute the basis for value cocreation; both enterprises and consumers must be involved in the process of value cocreation [17]. However, interactions between enterprises and consumers do not guarantee value creation [13]. Notably, the quality of these interactions is key to the creation of customer value [18], and enterprises must understand their consumers to effectively manage such interactions.

As demonstrated in the literature on value cocreation, value is created by interactions between enterprises and consumers. The objective of value creation is to increase the "use value" of consumers. Studies have analyzed the cocreation between two participants for a single value point. However, in practice, value creation may have several distinct value targets, and cocreation may include interactions between two or more participants; these multiparty interactions have not been discussed by studies on value cocreation. Therefore, the multiple interactions in value cocreation and their effects require further analysis.

2.2. Value of Sports Events. Studies on the value of sports events have covered extensive topics, primarily focusing on the evaluation of (1) value of sports events, (2) brand value of sports events, and (3) cultural value of sports events.

Huang et al. [19] constructed a framework for assessing sports event value and concluded that sports events value comprises two categories: utilization value and nonutilization value. Wang [20] developed an evaluation method for assessing customer value for sports events. $\mathrm{Li}$ and Yao [21] suggested that the goal of sports event evaluation should be to determine and create value. Yao and Liu [22] proposed the evaluation of brand value through a revenue modeling method that considers multiperiod excess revenue. Jiang and Zhong [23] constructed a sports event brand communication value system. Li and Yang [24] categorized the cultural value of sports events into two levels: self-value consciousness and social value consciousness. Studies have examined spectators' perceived value of sports events from the perspective of value cocreation. For example, Horbel et al. [5] explored the effects of value cocreation on the watching experience and perceived value of television audiences.

Studies have identified several aspects of the value of sports events. In addition, several studies have extensively discussed methods for evaluating such value. Value cocreation theory has also been applied in research on sports events; in particular, the influence of value cocreation activities on television sports audiences has been explored. However, the environment in which spectators are located differs substantially from that of television audiences, and the effect of value cocreation activities on spectators in sports events requires further clarification. Accordingly, further research is required to investigate the influence of value cocreation activities on spectators in sports events.

\subsection{Spectator Perceived Value of Sports Events. Service} quality influences spectators' perceived value, which in turn influences their behavioral intentions [25]. Sports spectators' perceived value influences their social capital through their attitudes [26]. Spectators' perceived quality of sports events can influence their behavioral intentions; the quality of a sports venue indirectly influences spectators' behavioral intentions through their perceived quality [27]. Spectators' perceived value constitutes the basis for spectators' overall perceived value of sports events [28]. For sports events, spectator perceived value comprises 9 aspects: entertainment, social value, status value, moral value, spiritual value, cognitive value, aesthetic value, ritual value, and negative value [29]. Studies on professional basketball games have revealed the following findings: (1) service quality can influence spectator satisfaction and perceived value, (2) spectator satisfaction and perceived value can influence the intentions of spectators to attend future games, and (3) 
spectator emotions can moderate the effect of service quality on spectators' perceived value [30].

Although studies have emphasized the role of spectators' perceived value of sports events, no study has discussed the cocreation of value for spectators. Numerous value cocreation interactions involving spectators and other actors in the context of sports event have been identified (i.e., spectators' interactions with organizers, athletes, and other participants). The effects of such interactions on value cocreation among spectators warrant further research.

In summary, value cocreation theory can be applied to comprehensively analyze the interactions between enterprises and consumers and the effects of these interactions on consumers' perceived value. Studies on sports events have explored the effect of value cocreation on television audiences of sports events. However, few studies have thoroughly explored multiparticipant, multivalue cocreation activities involving sports spectators. Accordingly, the present study investigated these interactions and their effects with the aim of extending existing research on value in sports events.

\section{Theory and Hypotheses}

Value cocreation theory suggests that interactions between enterprises and consumers can create considerable use value [13]. Consumer value comprises three aspects: enjoyment value, economic value, and relational value [31]. A study used SDL to analyze value cocreation activities and explored the effectiveness of customer participation in the creation of commercial and relational value; the findings of the mentioned study revealed that customer participation increases customer value and strengthens the relational link between customers and employees [32]. Although research on value creation has focused on the generation of both economic and relational extrinsic value, customer participation can also generate intrinsic attraction, which is the ability to feel pleasure from participation [33]. The SDL argument is that consumer goods do not have inherent value; instead, value is considered the result of the experience of consumption [1]. Thus, value cocreation also occurs through personalized consumption experiences [34], and experiences create value through the achievement of expected goals or provision of pleasure [35]. Consequently, spectator perceived value of sports events can be divided into three aspects: enjoyment value, economic value, and relational value.

The interactive behavior of spectators in sports events comprises interactions between spectators and athletes and interactions between spectators and staff. In the interactions between spectators and athletes, greater spectator participation is associated with greater athlete enthusiasm during competitions [36]. A study on value cocreation in sports events demonstrated that athletes exert a significant effect on spectator experience [5]. Spectators applaud and cheer for athletes during a competition, and athletes also interact with spectators through tokens of acknowledgment (e.g., waving at spectators). In tennis tournaments, spectators can take pictures with athletes, ask for autographs, and receive the athletes' gear at the end of the match. Staff-spectator interactions during a game are also crucial [36]. Spectators at sports events participate in activities such as ticket purchases, parking, ticket checks, security checks, admission, and event surveys. These activities require guidance, answers, and effort from staff members. Furthermore, spectators may require staff members to explain game-related information, such as the rules of the game [36]. Therefore, value cocreation between spectators and athletes and that between spectators and staff members both have substantial effects on spectators' perceived value [5].

In the present study, a conceptual model (Figure 1) of value cocreation through spectator-athlete and spectatorstaff interactions was established to investigate the effect of these multiparty interactions on spectators' perceived value and responses.

Spectator-athlete and spectator-staff interactions influence spectator perceived value. Spectator perceived value includes enjoyment value, economic value, and relational value. Increases in spectator perceived value can increase spectator satisfaction and loyalty, and spectator satisfaction can increase spectator loyalty.

\subsection{Value Cocreation and Spectator Perceived Value of Sports} Events. Value cocreation theory contends that value is not created by enterprises alone but through the combined efforts of enterprises and consumers [9]. The term "value" refers to use value; therefore, value can only be generated through consumer experience [2]. Through high-quality interactions, customers cocreate unique experiences with an enterprise, and value is thus cocreated by an enterprise and consumers [17]. A study suggested that interaction is the foundation for value cocreation [13]. A practice-oriented study investigated how value is generated from interactive behavior [37]. Research on Chinese consumers indicated that interactions can affect the value of consumer service experiences and that consumer involvement moderates this influence [38]. The characteristics of customer interactions substantially affect the perceived benefits of consumer value cocreation [39]. Therefore, interactions between enterprises and consumers influence consumer perceived value.

At sports events, spectator-athlete interactions influence spectator perceived value. Spectator-athlete interactions are crucial because they affect the atmosphere of an event and the psychological status of both athletes and spectators [40]. In some sporting competitions, athletes' indifference toward fans leads to spectator dissatisfaction, resulting in spectator opposition to both the athletes and their team [40] and a substantial decrease in the perceived value of supporting the athletes. In a tennis competition, inappropriate cheers from spectators distract athletes and reduce their morale, leading to disappointment among spectators [40]. Spectator-athlete interactions generate a spectator-athlete coexperience. New technologies and devices (e.g., mobile apps) have been introduced to increase the connection and interactions between athletes and spectators in long-distance running events [41]. For example, a handle-shaped device, namely, Synchronization Media of Athletes and Spectator through Haptic (SMASH), has been introduced to enable spectators of long-distance running competitions to obtain 


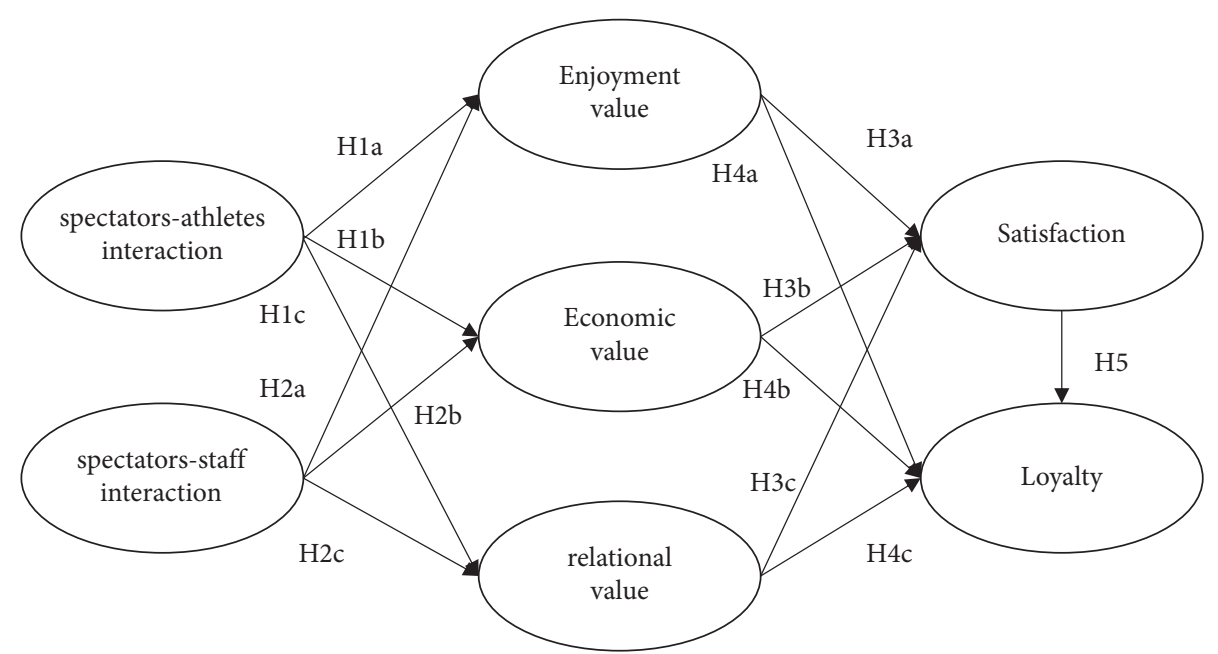

Figure 1: Conceptual model.

information about a runner's heartbeat through haptic feedback transmitted to the handheld device; this prompts the spectators to feel a sense of closeness with the athletes and the event at large [42] and thus increases the spectators' perceived value of watching the competitions. Another system, namely, Remote Supporter Feedback for LongDistance Runners (RUFUS), allows a runner to actively request spectators to start or stop cheering, which creates spectator engagement [42] and results in increased spectator perceived value. Spectators are not satisfied with simply cheering; they also desire more access to the athlete experience and closer interactions with athletes [43]. Spectators feel excited when athletes pay attention to them; thus, they attempt to engage in interactions with athletes [42].

Spectators' behavior (e.g., applause, cheering, and booing) can affect the performance of athletes and thus positively or negatively influence spectator perceived value [44]. Various sports have transitioned from entertainment to a service; athletes in sports events must have some direct personal contact with consumers (i.e., spectators [45]). Athletes in sports events are participants in the production of the sports events, and they must consider the needs of spectators [46]. In spectator evaluations of athletes, criteria such as appearance, behavior, and athletic skills are applied [46]. Athletes in sports events are subject to "interference" from groups during competitions, and such groups include spectators [46]. Therefore, a study investigated spectatorathlete interactions at sports events [46].

Commercial factors are considered in sports events; therefore, consumer demands (i.e., spectator demands) must be considered [46]. Spectators' needs can influence organizing committee members and athletes, and vice versa [46]. Spectator-athlete interactions constitute a form of "interconnection" or a relationship involving mutual responses [37]. Interactions between athletes and spectators increase the experiential value for spectators. Regarding consumer participation, consumer perceived value includes perceived enjoyment value, economic value, and relational value [31]. Therefore, we hypothesized the following.
H1. Interactions between athletes and spectators would significantly and positively influence spectator perceived value. Spectator perceived value includes enjoyment value (H1a), economic value (H1b), and relational value (H1c).

Collaboration and interactions between a company's frontline staff and customers are essential for the achievement of successful service outcomes and the concurrent enhancement of customer perceived value [47, 48]. For sports events, frontline staff members work on-site, and their interactions with spectators influence spectator perceived value. Staff-customer interactions increase the contact between staff and customers, who interact through their attitudes, voices, and gestures; this process increases cocreated value $[49,50]$. Value cocreation requires the participation of both frontline staff members and customers [51]. Therefore, staff-customer interactions have both direct and indirect effects on customer perceived value.

During sports events, interactions between spectators and organizers also influence spectator perceived value. Sports event venues are spaces where services are provided to spectators [36]. Competitions held at sports event venues tend to last for a long time and are highly professional; interactions between staff and spectators constitute a key component of an interactive relationship [36] because they influence spectator perceived value. The personalized services required by spectators and the nominal services provided by staff members may differ; therefore, staff members and spectators must interact to improve spectator experience and perceived value [36]. In spectator-staff interactions, the attitude and skill of staff members can influence spectators' perceived service quality [52], thus in turn affecting spectators' perceived value. The appearance, responses, guidance, explanations, organization, care, and services provided by staff members can all influence spectators' feelings during sports events and thus affect spectators' perceived value of their experiences [36]. The responsiveness of sports event staff members (including timely and effective responses to inquiries) is a key factor in the creation of value for spectators [53]. Spectator-staff interactions can 
substantially improve spectators' perceived value of their experiences. In the context of consumer participation, spectator perceived value comprises three aspects: enjoyment value, economic value, and relational value [31]. Therefore, we posited the second hypothesis as follows.

H2. Interactions between staff members and spectators would significantly and positively influence spectator perceived value. Spectator perceived value comprises enjoyment value $(\mathrm{H} 2 \mathrm{a})$, economic value $(\mathrm{H} 2 \mathrm{~b})$, and relational value ( $\mathrm{H} 2 \mathrm{c})$.

3.2. Spectator Perceived Value and Responses. The relationship between perceived value and customer satisfaction was verified in consumer behavior research [54]. Numerous studies have indicated that customer perceived value can significantly and positively influence customers' satisfaction toward the products or services that they have consumed $[55,56]$. In the context of sports events, spectators' perceived value can influence their satisfaction. Spectator satisfaction at sports events refers to the psychological state of the spectator, which stems from the spectator's comparison of their expectations and actual experience in relation to an event. Research indicated that performance and service quality at sports events can influence spectator satisfaction [46]; good performance and high service quality create high value for spectators. The satisfaction of spectators at sports events is primarily influenced by their perceived value, and this effect is asymmetrical [57].

Sports event spectators' perceived value based on their feelings, environmental experiences, consumer perception, and service perception is crucial for their satisfaction [58]. Calabuig et al. [30] identified a direct and positive relationship between perceived value and satisfaction with sports events. The relationship between perceived value and customer satisfaction was further demonstrated in the context of fitness centers [59]. A survey of World Women's Basketball League spectators revealed that good performance, reasonable ticket prices, interactions with athletes, and an emphasis on spectator opinions increase the satisfaction of the spectators [60]. When spectators perceive the value of sports events to be high, they feel that watching a game in such events is worthwhile and thus obtains high satisfaction. Spectator perceived value comprises three aspects: enjoyment value, economic value, and relational value [31]. Therefore, we posited the third hypothesis as follows.

H3. Spectator perceived value would significantly and positively affect spectator satisfaction. Spectator perceived value comprises enjoyment value (H3a), economic value $(\mathrm{H} 3 \mathrm{~b})$, and relational value $(\mathrm{H} 3 \mathrm{c})$.

Customer perceived value is an essential predictor of customer loyalty to a product or service [61]. Several studies have demonstrated that consumer perceived value can significantly and positively influence loyalty $[62,63]$. The value that sports events generate for spectators can influence the spectators' loyalty to the events. Spectator loyalty to sports events refers to spectators' positive feelings toward sports events and their regular viewing of such events. A study on sports tourism indicated that customers' perception of a travel destination's value can positively influence their loyalty to that destination [64]. A survey of spectators of Chinese professional basketball games revealed that performance, entertainment, and staff service quality can influence spectator loyalty to events [65]. Spectators' perceptions of the value of sports events can also significantly influence their loyalty to such events; for spectators, a higher perceived value of events is associated with a higher likelihood of watching sports events and higher level of loyalty to these events [66]. A study on track and field events demonstrated that spectators' perceived event value influences whether they watch the events [67]. Spectators watch track and field events when they perceive that these events provide value for money [67]. Higher perceived sports event value engenders increased spectator viewership and loyalty. Spectator perceived value comprises three aspects: enjoyment value, economic value, and relational value [31]. Therefore, the fourth hypothesis is outlined as follows.

H4. Spectator perceived value would significantly and positively affect spectator loyalty. Spectator perceived value comprises enjoyment value (H4a), economic value (H4b), and relational value $(\mathrm{H} 4 \mathrm{c})$.

3.3. Spectator Satisfaction and Loyalty. Several studies have demonstrated that customer satisfaction significantly influences customer loyalty [68]; hence, numerous enterprises have maintained customer loyalty by increasing customer satisfaction [69]. For sports events, spectator satisfaction is a key factor influencing spectator loyalty. Spectator satisfaction and pleasure result in an emotional resonance with an event; this emotional resonance leads to spectator loyalty [66]. A survey of Chinese Basketball Association spectators revealed that satisfaction with an event significantly and positively influences event loyalty [70]. Furthermore, a study of Women's Chinese Basketball Association tournament spectators revealed that spectator goodwill generated through long-term satisfaction with the tournament results in loyalty to the tournament [71]. A survey of spectators at the Wuhan Open also revealed that spectator satisfaction with the tournament has a significant positive effect on spectator loyalty [72]. Sports spectators who are satisfied with their experiences pertaining to an event tend to continue participating in the event and remain loyal to the event. Therefore, we posited the fifth hypothesis as follows.

H5. Spectator satisfaction for sports events would significantly and positively influence spectator loyalty.

\section{Methods}

4.1. Choice of Sample. In this study, spectators at the 2017 Wuhan Tennis Open were selected as respondents, and data were collected by distributing questionnaires to the spectators. The Wuhan Open is among the top three tennis tournaments in China. This event is also among the Premier 5 tournaments (i.e., Wuhan, Doha, Rome, Montreal, and 
Cincinnati) and among the top 10 Women's Tennis Association tennis tournaments. In 2017, 105,000 people watched the Wuhan Open.

The experiences of both players and spectators are crucial at the Wuhan Open, and various activities have been designed and implemented to increase interactions between athletes and spectators. These interactions include spectators picking sides, $\mathrm{Li} \mathrm{Na}$ (a professional Chinese player) teaching the spectators how to play tennis, athletes signing autographs for spectators, athletes taking photos with spectators, athletes presenting tournament supplies to spectators, and athletes visiting a carnival to interact with spectators. During the 2017 Wuhan Open, various activities were also implemented to promote interactions between staff members and spectators. For example, volunteers and staff members were widely available to answer spectator questions. Spectator satisfaction questionnaires were distributed to assess the watching experience of the spectators. Other forms of interactions at the Wuhan Open include the recruitment of spectators (through a membership center) to become members, who then visit the court or participate in activities such as the "I am the voice of the Wuhan Open" and "Wuhan Open in the community" events and on-site carnival events. These interactive activities have enhanced the spectator experience and substantially increased the value of watching the tournament. Hence, spectator experiences at the 2017 Wuhan Open were investigated to study the activities involved in value cocreation with sports spectators.

4.2. Measurement of Variables. The study variables were measured by adapting scales developed by previous research. Specifically, we adapted these scales to fit the context of sports. The scales were adapted by referencing mature scales developed in other studies, conducting group discussions regarding the relevance of the scales to the research question, modifying scale items, and inviting three experts in the field of sports management to provide suggestions for further modifications. Seven scales were developed: spectator-athlete interaction, spectator-staff interaction, enjoyment value, economic value, relational value, spectator satisfaction, and spectator loyalty scales. All scale items were scored on a 7 point Likert scale, with 1 and 7 indicating strongly disagree and strongly agree, respectively.

Spectator-athlete interactions and spectator-staff interactions were measured using two scales developed by Campos et al. [73]. Moreover, spectator perceived value (comprising three aspects such as enjoyment value, economic value, and relational value) was measured using a scale developed by Chi et al. (2012). Spectator satisfaction was measured using a scale developed by Buonincontri et al. [74]. Finally, spectator loyalty was measured using a scale developed by Zeithaml et al. [75].

4.3. Pilot Study. Prior to the formal research, 30 respondents with on-site viewing experience were selected to complete the questionnaire in order to ensure its accuracy. On the basis of the feedback provided by these respondents, the questionnaire items were further modified for clarity, and the resulting version was used as the final questionnaire.

4.4. Research Implementation. Data were collected through a survey of spectators at the 2017 Wuhan Open. Questionnaires were distributed to the spectators between September 22 and 30, 2017. To improve the response rate and ensure the quality of the questionnaire responses, a face-to-face survey method was applied. The investigators distributed the questionnaires to the spectators during game breaks at the event and waited with the spectators until they completed them. The investigators then provided explanations to the spectators whenever they considered an item to be unclear. A total of 572 questionnaires were distributed, 526 questionnaires were returned, and 500 questionnaires were determined to be valid. Accordingly, the questionnaire recovery rate and efficiency rate were $92 \%$ and $95 \%$, respectively. The demographics of the respondents are presented in Table 1.

\section{Results}

5.1. Measurement Model. AMOS 16.0 software was used to perform a confirmatory factor analysis for testing data reliability and validity. The results revealed that the measurement models had a good fit: $\chi^{2}(500)=420.112 ; \chi^{2}$ / $\mathrm{df}=1.603$; root mean square residual $=0.063$; goodness-offit index $(\mathrm{GFI})=0.943$; adjusted GFI $(\mathrm{AGFI})=0.918$; Tucker-Lewis index $(\mathrm{TLI})=0.984$; comparative fit index $(\mathrm{CFI})=0.988$; and root mean square error of approximation $($ RMSEA $)=0.035$. As presented in Tables 2 and 3, the composite reliability of all structural variables ranged from 0.7890 to 0.9625 , and the value of Cronbach's alpha ranged from 0.784 to 0.941 ; these are both greater than the recommended minimum of 0.6. Furthermore, the average variance extracted (AVE) was greater than the recommended minimum of 0.50 . These results demonstrate the good reliability of the measurement of related structural variables. The standardized factor loading of the structural variables was greater than 0.5 and was significant at the level of $\alpha=0.01$, indicating that the scale has high aggregate validity. Furthermore, the square roots of the AVE were greater than the correlation coefficients of its rows and columns, indicating that the scale has high discriminant validity.

5.2. Structural Model. The structural model had a good fit: $\chi^{2}$ $(500)=641.652 ; \quad \chi^{2} / \mathrm{df}=2.333 ; \quad \mathrm{GFI}=0.916 ; \quad \mathrm{AGFI}=0.885$; $\mathrm{TLI}=0.965 ; \mathrm{CFI}=0.972 ;$ and $\mathrm{RMSEA}=0.052$. Figure 2 displays the results obtained from a path analysis based on a structural equation model.

As revealed by structural equation model results, spectator-athlete interactions had a significant positive effect on enjoyment value $(\gamma=0.191 ; p<0.01)$, economic value $(\gamma=0.169 ; p<0.01)$, and relational value $(\gamma=0.262$; $p<0.01)$. Moreover, spectator-athlete interactions had a significant positive effect on enjoyment value $(\gamma=0.465$; $p<0.01)$, economic value $(\gamma=0.614 ; p<0.01)$, and relational 
TABle 1: Sample demographics.

\begin{tabular}{lc}
\hline Index & Percentage (\%) \\
\hline Gender & 48.6 \\
Male & 51.4 \\
Female & \\
Education & 7.8 \\
High school and below & 24.6 \\
College & 54.8 \\
Undergraduate & 12.8 \\
Master's degree and above & 6.2 \\
Age & 57.8 \\
$10-17$ & 21.6 \\
$18-25$ & 10.8 \\
$26-33$ & 3.6 \\
$34-41$ & \\
$42+$ & 20.8 \\
Sports special & 79.2 \\
Yes & \\
No & \\
\hline
\end{tabular}

TABle 2: Questionnaire items.

\begin{tabular}{|c|c|c|c|c|c|}
\hline Variable & Loading & $\begin{array}{l}\text { Standard } \\
\text { deviation }\end{array}$ & $\begin{array}{c}\text { Average variance } \\
\text { extracted }\end{array}$ & $\begin{array}{l}\text { Composite } \\
\text { reliability }\end{array}$ & $\begin{array}{c}\text { Cronbach's } \\
\alpha\end{array}$ \\
\hline $\begin{array}{l}\text { Athlete cocreation } \\
\text { I can contact the athletes directly. } \\
\text { I can get in touch with the athletes to better understand } \\
\text { them. } \\
\text { My experience with the athletes is unforgettable. } \\
\text { My contact with athletes makes me feel happy. }\end{array}$ & $\begin{array}{l}0.620 \\
0.831 \\
0.909 \\
0.861\end{array}$ & 0.1540 & 0.6606 & 0.8843 & 0.881 \\
\hline $\begin{array}{l}\text { Organization cocreation } \\
\text { I can communicate with the event staff. } \\
\text { My opinions are important to the event staff. } \\
\text { My experience with the event staff is unforgettable. } \\
\text { My contact with the event staff makes me feel happy. }\end{array}$ & $\begin{array}{l}0.595 \\
0.722 \\
0.925 \\
0.880\end{array}$ & 0.1000 & 0.6263 & 0.8670 & 0.869 \\
\hline $\begin{array}{l}\text { Enjoyment value } \\
\text { I like to watch and participate in events. } \\
\text { I watch the game to feel content both mentally and } \\
\text { physically. } \\
\text { Watching the game is fun. } \\
\text { Watching the game makes me feel happy. }\end{array}$ & $\begin{array}{l}0.841 \\
0.918 \\
0.904 \\
0.932\end{array}$ & 0.0750 & 0.8090 & 0.9442 & 0.941 \\
\hline $\begin{array}{l}\text { Economic value } \\
\text { The experience of watching the event is worth the cost. } \\
\text { The competition is always held for the audience's } \\
\text { enjoyment. } \\
\text { My opinions can influence the service quality of future } \\
\text { events. }\end{array}$ & $\begin{array}{l}0.697 \\
0.825 \\
0.709\end{array}$ & 0.0880 & 0.5564 & 0.7890 & 0.784 \\
\hline $\begin{array}{l}\text { Relational value } \\
\text { I managed to contact the departments involved in the } \\
\text { competition. } \\
\text { I established a good relationship with the departments } \\
\text { involved in the competition. } \\
\text { I established a deep connection with the departments } \\
\text { involved in the competition. }\end{array}$ & $\begin{array}{l}0.984 \\
0.968 \\
0.866\end{array}$ & 0.1700 & 0.8957 & 0.9625 & 0.936 \\
\hline $\begin{array}{l}\text { Satisfaction } \\
\text { I am very satisfied with this event. } \\
\text { This event is well-organized. } \\
\text { This event is as good as I expected. } \\
\text { Overall, I am very satisfied with this event. }\end{array}$ & $\begin{array}{l}0.855 \\
0.948 \\
0.892 \\
0.905\end{array}$ & 0.1000 & 0.8111 & 0.9449 & 0.940 \\
\hline
\end{tabular}


TABLE 2: Continued.

\begin{tabular}{|c|c|c|c|c|c|}
\hline Variable & Loading & $\begin{array}{r}\text { Standard } \\
\text { deviation }\end{array}$ & $\begin{array}{c}\text { Average variance } \\
\text { extracted }\end{array}$ & $\begin{array}{c}\text { Composite } \\
\text { reliability }\end{array}$ & $\begin{array}{c}\text { Cronbach's } \\
\alpha \\
\end{array}$ \\
\hline \multicolumn{6}{|l|}{ Loyalty } \\
\hline I will tell others that this event was well-organized. & 0.863 & & & & \\
\hline I will recommend others to watch this event. & 0.934 & & & & \\
\hline $\begin{array}{l}\text { I will encourage my friends and family to participate in } \\
\text { this event. }\end{array}$ & 0.927 & 0.0860 & 0.7258 & 0.9291 & 0.927 \\
\hline This event is one of my favorite events. & 0.807 & & & & \\
\hline I will come to watch this event next year. & 0.708 & & & & \\
\hline
\end{tabular}

TABLE 3: Correlation coefficient of latent variables.

\begin{tabular}{|c|c|c|c|c|c|c|c|}
\hline Constructs and items & $\begin{array}{l}\text { Organization } \\
\text { cocreation }\end{array}$ & $\begin{array}{l}\text { Athletes } \\
\text { cocreation }\end{array}$ & $\begin{array}{c}\text { Enjoyment } \\
\text { value }\end{array}$ & $\begin{array}{c}\text { Economic } \\
\text { value }\end{array}$ & $\begin{array}{c}\text { Relational } \\
\text { value }\end{array}$ & Satisfaction & Loyalty \\
\hline $\begin{array}{l}\text { Organization } \\
\text { cocreation }\end{array}$ & 0.791 & & & & & & \\
\hline Athletes cocreation & 0.543 & 0.813 & & & & & \\
\hline Enjoyment value & 0.567 & 0.450 & 0.899 & & & & \\
\hline Economic value & 0.738 & 0.535 & 0.666 & 0.746 & & & \\
\hline Relational value & 0.628 & 0.451 & 0.385 & 0.617 & 0.946 & & \\
\hline Satisfaction & 0.588 & 0.444 & 0.474 & 0.731 & 0.474 & 0.901 & \\
\hline Loyalty & 0.621 & 0.446 & 0.759 & 0.725 & 0.512 & 0.801 & 0.852 \\
\hline
\end{tabular}

Note. Data on the diagonal are square roots (average variance extracted).

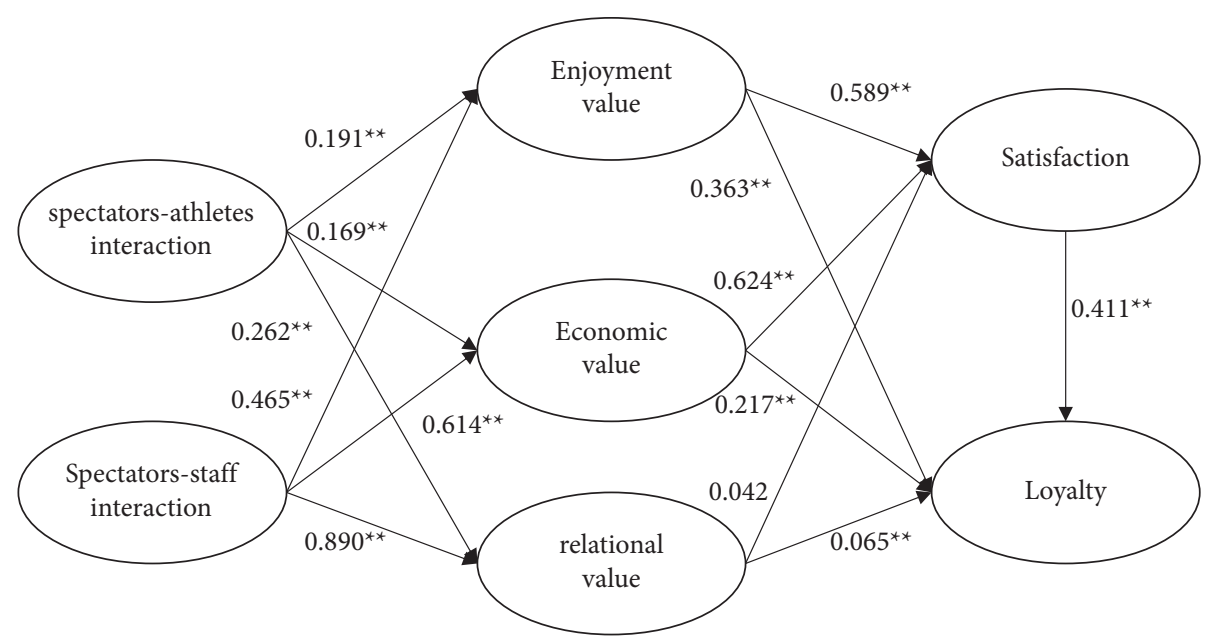

FIGURE 2: Path analysis results. ${ }^{* *} p<0.01 ;{ }^{*} p<0.05$.

value $(\gamma=0.890 ; p<0.01)$. Enjoyment value had a significant positive effect on spectator satisfaction $(\gamma=0.589 ; p<0.01)$ and spectator loyalty $(\gamma=0.363 ; p<0.01)$. Economic value had a significant positive effect on spectator satisfaction $(\gamma=0.624 ; \quad p<0.01)$ and spectator loyalty $(\gamma=0.217$; $p<0.01)$. Relational value had no significant effect on spectator satisfaction $(\gamma=0.042 ; p>0.5)$, but it had a significant positive effect on spectator loyalty $(\gamma=0.065$; $p<0.01)$. Spectator satisfaction also had a significant positive effect on spectator loyalty $(\gamma=0.411 ; p<0.01)$.

\section{Discussion and Conclusion}

6.1. Discussion. The implementation of value cocreation activities for sports events can considerably improve the response of television audiences [5]. By conducting a survey at the 2017 Wuhan Open, this study demonstrated that value cocreation activities have positive effects on spectator psychology and behavior. Moreover, this study investigated value cocreation in the context of sports spectators and analyzed multiple interactions in value cocreation and their 
effects. Value cocreation activities for spectators differ from those for television audiences. For television audiences, the team, consumption background, and consumption atmosphere are key factors influencing value cocreation [5]. For sports spectators, the main activities involved in value cocreation are spectator-staff interactions and spectatorathlete interactions. The mechanisms underlying value cocreation interactions also differ between sports spectators and television audiences. Among television audiences, value cocreation activities improve audience response by improving their event experience. For spectators, value cocreation activities affect their satisfaction with and loyalty to events by enhancing spectator perceived value.

6.2. Conclusion. This study investigated value cocreation activities involving sports spectators and the response of the spectators to multiple interactions in such activities. Spectator perceived value was used as an intermediate variable. On the basis of the study findings, we can draw the following conclusions. First, multiple interactions in value cocreation significantly and positively influence spectator perceived value. Spectator-athlete interactions and spectator-staff interactions both significantly and positively influence perceived enjoyment value, economic value, and relational value. Second, spectator perceived value partially influences spectator satisfaction. Spectator perceived enjoyment value and economic value significantly and positively influence spectator satisfaction, whereas spectator perceived relational value has no significant effect on spectator satisfaction. Third, spectator perceived value has a significant effect on spectator loyalty. The perceived enjoyment value, economic value, and relational value of sports spectators have a significant positive effect on spectators' loyalty. Fourth, spectator satisfaction has a significant positive effect on spectator loyalty. The multiple interactions in value cocreation at sports events can significantly increase spectator perceived value, thus increasing spectator satisfaction and loyalty to such events. Therefore, organizers of sports events should further develop all interactions that lead to value cocreation.

6.3. Theoretical Implications. First, this study extends the literature on value cocreation at sports events by exploring the mechanisms underlying the influence of value cocreation activities involving sports spectators. A previous study examined transformative value cocreation for Olympic athletes to improve player well-being [76]. Horbel [5] introduced the theory of value cocreation in sports events and explored value cocreation activities involving television audiences of sports events and the mechanisms underlying the effects of such activities. Another study examined the effects of interactions between spectators on value creation for such spectators [77]. Value cocreation behavior can influence customer satisfaction and loyalty because of identification in the context of a team sports event [78]. The present study explored value cocreation in the context of sports events and the mechanisms underlying its influence event spectators; thus, the study findings extend the literature on value cocreation in sports events.
Second, the role of spectator perceived value in value cocreation in the context of sports events was discussed, thereby extending research on the mechanisms underlying the effects of value cocreation activities on spectator responses in the context of sports events. Event experience is a key mediating variable related to spectator response, and value cocreation activities influence spectator responses through spectator experiences [5]. A previous study explored the components of game consumers' perceived value [79], but it did not discuss the role of perceived value in shaping spectators' experience. The present study investigated the effects of value cocreation activities on spectator responses by using spectator perceived value as a mediating variable. Value cocreation activities were demonstrated to improve spectator responses by increasing spectator perceived value. These results further elucidate the mechanism underlying the effect of value cocreation on spectator responses.

Third, the effects of multiple interactions in value cocreation activities on spectators were explored in the context of sports events, thus extending the literature on value cocreation theory. Traditional value cocreation theory describes how value cocreation interaction between firms and consumers influence consumer perceived value. Numerous studies have analyzed value cocreation interactions. In the present study, the effects of spectator-staff and spectatorathlete interactions on spectator perceived value of sports events were investigated. The present study also further extends value cocreation theory by exploring the effects of multiple interactions in value cocreation activities.

6.4. Practical Implications. First, to increase the satisfaction of sports spectators and enable them to participate while watching an event, organizers of sports events should design interactive activities that enable communication between spectators and relevant groups. Interactive activities involving spectators and staff members could include on-site games, lotteries, surveys, gift-giving, visits, and sports knowledge lectures. These activities could increase spectator satisfaction and loyalty to the events. Interactive activities involving spectators and athletes could include spectators participating in autograph and photograph sessions, giving gifts to athletes, viewing athletes' training, and receiving technique-related tips from athletes; these activities could also increase spectator satisfaction and loyalty to the events.

Second, organizers of sports events should invest more resources in staff-spectator interactions and less resources in athlete-spectator interactions when designing interactive activities for sports events. In the present study, spectatorstaff interactions had a relatively substantial influence on spectator perceived value and spectator-athlete interactions had a smaller influence. Therefore, organizers of sports events should devote more resources, including financial and material resources, to designing activities supporting spectator-staff interactions. However, organizers should still reserve a small number of interactive activities and a small quantity of resources for athlete-spectator interactions. This is the most efficient method for increasing spectator perceived value in terms of return on investment; these 
improvements can increase spectator satisfaction and loyalty to an event.

Third, organizers of sports events should increase multidimensional spectator perceived value. Spectator perceived value of sports events encompasses three aspects: enjoyment value, economic value, and relational value. Therefore, organizers of sports events must provide more interactive and entertaining programs to increase the perceived entertainment value of such events and thus increase spectator perceived entertainment value. By improving the quality of a competition and the service quality of sports events and by providing cost-effective catering services, organizers can prompt spectators to perceive that they are getting their money's worth. Organizers of sports events should strengthen connections with spectators before, during, and after the events; they should increase spectator loyalty through the use of membership clubs, thereby increasing the perceived relational value of spectators.

6.5. Limitations and Future Research. This study has several limitations that can be addressed in future research. First, the study investigated only on-site spectator-athlete interactions and spectator-staff interactions; however, other value cocreation interactions may exist. Future studies could explore other interactions in other sports events. Second, the study investigated value cocreation for only spectator perceived value; however, other types of value (e.g., sponsorship value and communication value) may also be influenced. Value cocreation for these types of value could be investigated by future studies on sports event. Third, the study respondents were spectators at the 2017 Wuhan Open; the generalizability of the findings should be tested by applying the questionnaire to other sporting events.

\section{Data Availability}

The data used to support this study are obtained from the corresponding author.

\section{Conflicts of Interest}

The authors declare that they have no conflicts of interest.

\section{Acknowledgments}

The study is funded by (1) Young and Middle Aged Scientific Research Team of Wuhan Sports University in 2021 (21KT18); (2) Philosophy and Social Science Research Project of Hubei Education Department (19Y099); and (3) Scientific Research Project of Hubei Education Department (B2021186). This manuscript was edited by Wallace Academic Editing.

\section{References}

[1] S. L. Vargo and R. F. Lusch, "The four service marketing myths," Journal of Service Research, vol. 6, no. 4, pp. 324-335, 2004.
[2] C. Grnroos and A. Ravald, "Service as business logic: implications for value creation and marketing," Journal of Service Management, vol. 22, no. 1, pp. 5-22, 2011.

[3] N. Erhardt, C. Martin-Rios, and E. Chan, "Value co-creation in sport entertainment between internal and external stakeholders," International Journal of Contemporary Hospitality Management, vol. 31, no. 11, pp. 4192-4210, 2019.

[4] H. Woratschek, C. Horbel, and B. Popp, "The sport value framework - a new fundamental logic for analyses in sport management," European Sport Management Quarterly, vol. 14, no. 1, pp. 6-24, 2014.

[5] C. Horbel, B. Popp, H. Woratschek, and B. Wilson, "How context shapes value co-creation: spectator experience of sport events," Service Industries Journal, vol. 36, no. 11-12, pp. 510-531, 2016.

[6] J. D. Chandler and S. L. Vargo, "Contextualization and valuein-context: how context frames exchange," Marketing Theory, vol. 11, no. 1, pp. 35-49, 2011.

[7] M. Li, S. Hofacre, and D. Mahony, Economics of Sport. Morgantown, WV, Fitness Information Technology, 2001.

[8] A. F. Payne, K. Storbacka, and P. Frow, "Managing the cocreation of value," Journal of the Academy of Marketing Science, vol. 36, no. 1, pp. 83-96, 2008.

[9] J. Williams and R. Aitken, "The service-dominant logic of marketing and marketing ethics," Journal of Business Ethics, vol. 102, no. 3, pp. 439-454, 2011.

[10] S. L. Vargo and R. F. Lusch, "Evolving to a new dominant logic for marketing," Journal of Marketing, vol. 68, no. 1, pp. 1-17, 2004.

[11] M. Bieler, P. Maas, L. Fischer, and N. Rietmann, "Enabling cocreation with transformative interventions: an interdisciplinary conceptualization of consumer boosting," Journal of Service Research, vol. 12, Article ID 109467052110036, 2021.

[12] C. K. Prahalad and V. Ramaswamy, "Co-opting customer competence," Harvard Business Review, vol. 78, no. 1, pp. 79-90, 2000.

[13] C. Grönroos and P. Voima, "Critical service logic: making sense of value creation and co-creation," Journal of the Academy of Marketing Science, vol. 41, no. 2, pp. 133-150, 2013.

[14] D. Scaraboto and B. Figueiredo, "Express: how consumer orchestration work creates value in the sharing economy," Journal of Marketing, 2021.

[15] A. Eletxigerra, J. M. Barrutia, and C. Echebarria, "Expanding the task-dominant value cocreation narrative: the role of consumer expertise and social and mental processes," Journal of Travel Research, Article ID 004728752110172, 2021.

[16] S. Wikström, "The customer as co-producer," European Journal Of Marketing, vol. 30, no. 4, pp. 6-14+19, 2013.

[17] C. K. Prahalad and V. Ramaswamy, The Future of Competition: Co-creating Unique Value with Customers, Harvard Business Press, Boston, MA, USA, 2004a.

[18] A. Fyrberg and R. Jüriado, "What about interaction?" Journal of Service Management, 2009.

[19] H. Y. Huang, Q. A. Lu, C. N. Fang, Z. M. Mo, and C. B. Shi, "Research on value assessment of sports competitions," Journal of Shanghai University of Sport, vol. 32, no. 01, pp. 20-24, 2008.

[20] K. Wang, "Ti Yu Sai Shi Gu Ke Jia Zhi Ping Jia Fang Fa Ji Shi Zheng Yan Jiu," Master's Dissertation, Capital University of Physical Education and Sports, Beijing, China, 2009.

[21] N. Z. Li and Q. Yao, "Evaluation of sports competitions," Assessing value and creating value Journal of Shanghai University of Sport, vol. 33, no. 4, pp. 1-4, 2009. 
[22] Q. Yao and D. F. Liu, "Evaluation method and model of the brand value of sports events," Journal of Shanghai University of Sport, vol. 40, no. 2, pp. 62-66+73, 2016.

[23] J. Z. Jiang and B. S. Zhong, "A study of the principle and method of the sports games brand communication value evaluation system," Journal of Beijing Sport University, vol. 31, no. 2, pp. 159-161+164, 2008.

[24] C. F. Li and Z. Y. Yang, "Preliminary exploration of the cultural value of sporting events," Journal of Guangzhou Sport University, vol. 36, no. 5, pp. 26-29, 2016.

[25] K. K. Byon, J. J. Zhang, and T. A. Baker, "Impact of core and peripheral service quality on consumption behavior of professional team sport spectators as mediated by perceived value," European Sport Management Quarterly, vol. 13, no. 2, pp. 232-263, 2013.

[26] L. Gau, "Development of a model connecting self-directive value and satisfaction of sociability needs in sport spectators," Social Behavior and Personality: An International Journal, vol. 41, no. 5, pp. 795-803, 2013.

[27] K. W. Byon, "Impact of market demand and game support programs on consumption levels of professional team sport spectators as mediated by perceived value," Dissertations \& Theses Gradworks, University of Florida, FL, USA, 2008.

[28] D. S. Robert, "An integrated model of value equity in spectator sports: conceptual framework and empirical results," Dissertations \& Theses - Gradworks, Florida State University, FL, USA, 2008.

[29] L. S. Gau, "Examining the values associated with spectator sports and the relationships between the values and sport spectator behavior," Dissertations \& Theses - Gradworks, Florida State University, FL, USA, 2007.

[30] V. G. Prado and J. P. Núñez, "Spectator emotions: effects on quality, satisfaction, value, and future intentions," Journal of Business Research, vol. 68, no. 7, pp. 1445-1449, 2015.

[31] C. K. Yim, K. W. Chan, and S. S. K. Lam, "Do customers and employees enjoy service participation? Synergistic effects of self- and other-efficacy," Journal of Marketing, vol. 76, no. 6, pp. 121-140, 2012.

[32] K. W. Chan, C. K. Yim, and S. S. K. Lam, "Is customer participation in value creation a double-edged sword? Evidence from professional financial services across cultures," Journal of Marketing, vol. 74, no. 3, pp. 48-64, 2010.

[33] P. A. Dabholkar, "How to improve perceived service quality by increasing customer participation," in Proceedings of the 1990 Academy of Marketing Science (AMS) Annual Conference, pp. 483-487, Springer, Phoenix, Arizona, January 2015.

[34] C. K. Prahalad and V. Ramaswamy, "Co-creation experiences: the next practice in value creation," Journal of Interactive Marketing, vol. 18, no. 3, pp. 5-14, 2004b.

[35] B. J. Babin, W. R. Darden, and M. Griffin, "Work and/or fun: measuring hedonic and utilitarian shopping value," Journal of Consumer Research, vol. 20, no. 4, pp. 644-656, 1994.

[36] M. X. Jia and H. J. Zhu, "Research on the management of spectator service quality in sport event based on the theory of service interaction," Journal of Xi'an Physical Education University, vol. 30, no. 2, pp. 129-136, 2013.

[37] P. Echeverri and P. Skålén, "Co-creation and co-destruction: a practice-theory based study of interactive value formation," Marketing Theory, vol. 11, no. 3, pp. 351-373, 2011.

[38] G. Q. Guo and N. J. Sun, "An empirical research about the impact of perceived interaction style on experiential value-- and discussing the mediating effect of newcomer adjustment,” Business Review, vol. 24, no. 12, pp. 72-83, 2012.
[39] S. Nambisan and R. A. Baron, "Virtual customer environments: testing a model of voluntary participation in value Cocreation activities," Journal of Product Innovation Management, vol. 26, no. 4, pp. 388-406, 2009.

[40] Y. C. Sun, Y. L. Zhang, and J. Cai, "Promotion strategies for athlete-spectator interaction," Journal of Physical Education Institute of Shanxi Normal University, vol. 26, no. 3, pp. 10-13, 2011.

[41] B. Tao, N. Berthouze, A. Singh, and E. Costanza, "Understanding the shared experiences of runners and spectators in long-distance running events," in Proceedings of the CHI Conference on Human Factors in Computing Systems Proceedings (CHI 2019), pp. 4-9, Glasgow, Scotland, UK, May 2019.

[42] M. S. Iekura, H. Hayakawa, K. Onoda, Y. Kamiyama, K. Minamizawa, and M. Inami, "SMASH: synchronization media of athletes and spectator through haptic," in Proceedings of the SIGGRAPH Asia 2015 Mobile Graphics and Interactive Applications, pp. 1-2, Kobe, Japan, November 2015.

[43] F. Curmi, M. A. Ferrario, J. Southern, and J. Whittle, "HeartLink: open broadcast of live biometric data to social networks," in Proceedings of the SIGCHI CHI'13 Conference on Human Factors in Computing Systems, Paris, France, May 2013.

[44] R. N. Singer, "Effect of spectators on athletes and non-athletes performing a gross motor task," Research Quarterly of the American Association for Health, Physical Education, and Recreation, vol. 36, no. 4, pp. 473-482, 1965.

[45] H. S. Becker, "The professional dance musician and his audience," American Journal of Sociology, vol. 57, no. 2, pp. 136-144, 1951.

[46] A. G. Ingham and M. D. Smith, "Social implications of the interaction between spectators and Athletes1," Exercise and Sport Sciences Reviews, vol. 2, no. 1, pp. 189-224, 1974.

[47] M. Jo Bitner, W. T. Faranda, A. R. Hubbert, and V. A. Zeithaml, "Customer contributions and roles in service delivery," International Journal of Service Industry Management, vol. 8, no. 3, pp. 193-205, 1997.

[48] J. R. K. Mccoll, S. L. Vargo, T. S. Dagger, J. C. Sweeney, and Y. V. Kasteren, "Health care customer value cocreation practice styles," Journal of Service Research, vol. 15, no. 4, pp. 370-389, 2012.

[49] M. g. Ivanova, "Culture in business relationship interaction: an individual perspective," Journal of Business \& Industrial Marketing, vol. 30, no. 5, pp. 608-615, 2015.

[50] I. O. Karpen, L. L. Bove, B. A. Lukas, and M. J. Zyphur, "Service-dominant orientation: measurement and impact on performance outcomes," Journal of Retailing, vol. 91, no. 1, pp. 89-108, 2015.

[51] C. Grönroos, "A service perspective on business relationships: the value creation, interaction and marketing interface," Industrial Marketing Management, vol. 40, no. 2, pp. 240-247, 2011.

[52] G. C. M. v. Leeuwen, R. P. Baa Yen, I. J. Holb, and M. J. Jeger, "Distinction of the Asiatic brown rot fungus Monilia polystroma sp. nov. from M. fructigena," Mycological Research, vol. 106, no. 4, pp. 444-451, 2002.

[53] K. J. Gergen, "Social psychology as history," Journal of Personality and Social Psychology, vol. 26, no. 2, pp. 309-320, 1973.

[54] M. Edward and S. Sahadev, "Role of switching costs in the service quality, perceived value, customer satisfaction and 
customer retention linkage," Asia Pacific Journal of Marketing \& Logistics, vol. 23, no. 3, pp. 327-345, 2011.

[55] W.-M. Hur, Y. Kim, and K. Park, "Assessing the effects of perceived value and satisfaction on customer loyalty: a 'green' perspective," Corporate Social Responsibility and Environmental Management, vol. 20, no. 3, pp. 146-156, 2013.

[56] S. M. Meng, G. S. Liang, and S. H. Yang, "The relationships of cruise image, perceived value, satisfaction, and post-purchase behavioral intention on Taiwanese tourists," African Journal of Business Management, vol. 5, no. 1, pp. 19-29, 2011.

[57] H. Z. You, "An empirical study on the asymmetrical relationship between service attributes and overall spectator satisfaction," Sport Science, vol. 35, no. 3, pp. 52-56, 2014.

[58] Q. Fang and Z. G. Wang, "Construction of audience satisfaction assessment index system of great sports event," Journal of sports adult education, vol. 33, no. 4, pp. 30-33, 2017.

[59] P. G. R. F. García, J. F. Gavira, L. C. Vélez, and A. B. García, "The effects of service convenience and perceived quality on perceived value, satisfaction and loyalty in low-cost fitness centers," Sport Management Review, vol. 21, no. 3, pp. 250262, 2018.

[60] A. L. Yu, "Investigation on the characteristics, expectation and satisfaction of spectators watching the international women basketball league match in Shaoxing," China sport science and technology, vol. 43, no. 3, pp. 31-35+46, 2007.

[61] Z. Yang and R. T. Peterson, "Customer perceived value, satisfaction, and loyalty: the role of switching costs," Psychology and Marketing, vol. 21, no. 10, pp. 799-822, 2004.

[62] R. Eid, "Integrating Muslim customer perceived value, satisfaction, loyalty and retention in the tourism industry: an empirical study," International Journal of Tourism Research, vol. 17, no. 3, pp. 249-260, 2015.

[63] C. A. Gumussoy and B. Koseoglu, "The effects of service quality, perceived value and price fairness on hotel customers satisfaction and loyalty," Journal of Economics, Business and Management, vol. 4, no. 9, pp. 523-527, 2016.

[64] Y. Jeong and S. Kim, "A study of event quality, destination image, perceived value, tourist satisfaction, and destination loyalty among sport tourists," Asia Pacific Journal of Marketing \& Logistics, vol. 32, no. 4, pp. 940-960, 2020.

[65] M. Zhang, X. Z. Wu, and N. Tang, "A study on the impact of professional basketball event quality on viewers' intention to return," Sports culture guide, vol. 32, no. 10, pp. 90-93, 2014.

[66] Z. Y. Zheng and T. Lu, "The meanings and measurement of fans' loyalty degree for sport events," Journal of Jinggangshan university, vol. 28, no. 1, pp. 62-65, 2007.

[67] R. K. Wang, "The analysis of influencing factors of Chinese spectators 'watching track and field events," Sports Sciences Researches, vol. 12, no. 3, pp. 49-52, 2008.

[68] Y. Xu, G. Wang, and P. Zhao, "The Moderating effect of quality attribute perceptual change on satisfaction-loyalty relationship," Nankai Business Review, vol. 16, no. 4, pp. 114-123, 2013.

[69] C. Fornell, M. D. Johnson, E. W. Anderson, J. Cha, and B. E. Bryant, "The American customer satisfaction index: nature, purpose, and findings," Journal of Marketing, vol. 60, no. 4, pp. 7-18, 1996.

[70] L. Y. Li and Y. L. Tao, "On the influencing factors and the upgrade path of fan loyalty of CBA-based on the perspective of the theory of customer loyalty," Journal of Harbin Institute of Physical Education, vol. 29, no. 5, pp. 63-66, 2011.
[71] C. Qin, An Empirical Study on the Loyalty of the Audience in the WCBA Taiyuan Competition Area, Master's Dissertation, Shanxi university, Shanxi, China, 2015.

[72] Z. ., G. Wang, X. L. Cai, K. Y. Zhang, C. Y. Wu, and J. J. Li, "Research on the relationship between Chinese spectator satisfaction and spectator loyalty in sports events--data from 2015 Wuhan Tennis Open," Hubei sports science, vol. 35, no. 12, pp. 1056-1063, 2016.

[73] A. C. Campos, J. Mendes, P. O. d. Valle, and N. Scott, "Cocreating animal-based tourist experiences: attention, involvement and memorability," Tourism Management, vol. 63, no. 12, pp. 100-114, 2017.

[74] P. Buonincontri, A. Morvillo, F. Okumus, and M. V. Niekerk, "Managing the experience co-creation process in tourism destinations: empirical findings from Naples," Tourism Management, vol. 62, pp. 264-277, 2017.

[75] V. A. Zeithaml, L. L. Berry, and A. Parasuraman, "The behavioral consequences of service quality," Journal of Marketing, vol. 60, no. 2, pp. 31-46, 1996.

[76] R. Mulcahy and E. Luck, "Row! Row! Row your boat! Transformative value cocreation and codestruction in elite and olympic rowers," Journal of Sport Management, vol. 34, no. 4, pp. 354-366, 2020.

[77] N. L. Koenig, Y. Asaad, and A. Palmer, "Sports events and interaction among spectators: examining antecedents of spectators' value creation," European Sport Management Quarterly, vol. 18, no. 2, pp. 193-215, 2018.

[78] H. Woratschek, C. Horbel, and B. Popp, "Determining customer satisfaction and loyalty from a value co-creation perspective," Service Industries Journal, vol. 40, no. 11-12, pp. 777-799, 2020.

[79] T. Kunkel, J. P. Doyle, and A. Berlin, "Consumers' perceived value of sport team games-A multidimensional approach," Journal of Sport Management, vol. 31, no. 1, pp. 80-95, 2017. 